\title{
Possibility of a Chemical Floral Filter in Sisyrinchium rosulatum to Syrphinae Hoverflies
}

\author{
Hidehiro Inagaki*, Nakatani So, Saruta Yuto \\ Shizuoka University, Fujieda, Japan.
}

How to cite this paper: Hidehiro Inagaki, Nakatani So, Saruta Yuto. (2020) Possibility of a Chemical Floral Filter in Sisyrinchium rosulatum to Syrphinae Hoverflies. International Journal of the Science of Food and Agriculture, 4(4), 379-382. DOI: $10.26855 /$ ijfsa.2020.12.003

Received: August 27, 2020

Accepted: September 26, 2020

Published: October 14, 2020

*Corresponding author: Hidehiro Inagaki, Shizuoka University, Fujieda, Japan.

Email: inagaki.hidehiro@shizuoka.ac.jp

\begin{abstract}
Syrphinae hoverflies are important insects in agriculture because they are natural enemies of aphids and excellent pollinators. For effective conservation and habitat management of the Syrphinae, it is important to understand which flowers they visit. So far, we have demonstrated that the flowers visited by Syrphinae have flat, simple shapes. However, the annual blue-eyed grass (Sisyrinchium rosulatum) is an exception because, even though it has flat, simple flowers, there have been no observations of Syrphinae visiting it. In this study, therefore, we hypothesized that the Syrphinae avoid $S$. rosulatum because its flower scent acts as a filter. We, therefore, tested whether the Syrphinae would avoid S. rosulatum flowers even under restricted, closed conditions, and checked the Syrphinae antipathy to the flower scent of $S$. rosulatum using a T-shaped tube. Our results confirmed that the Syrphinae seldom visit $S$. rosulatum flowers even in a closed environment. Our next examination of Syrphinae selectivity showed that the hoverflies preferred Oxalis corniculata to S. rosulatum. In addition, Syrphinae selected an "empty" option rather than S. rosulatum. These results confirmed that Syrphinae avoided the flowers of $S$. rosulatum. Moreover, it is suggested that Syrphinae avoid the flower because of the scent because they were unable to visually identify the flowers in the experiment using T-shaped tubes.
\end{abstract}

\section{Keywords}

Functional biodiversity, Syrphinae, annual blue-eyed grass (Sisyrinchium rosulatum), floral filter

\section{Introduction}

Agriculture depends upon ecosystem services created by functional biodiversity in the agricultural environment [1, 2]. The current thinking is that native useful organisms in agro-ecosystems are important for effective, sustainable agriculture [2-6]. Weed vegetation management is an effective method of conserving functional biodiversity in farmland [7]. However, depending on the species, weeds may be a source of natural biological control agents or, conversely, pest insects [8].

Syrphinae hoverflies are one of the most important insects in Japanese agriculture, since their larvae are the natural enemies of aphids, and the adults are excellent pollinators of vegetables and fruits $[9,10]$. The Syrphinae are insects that can be expected to survive in the green areas around farmland because of their low mobility [11-16]. Therefore, it is important to know which flowers the Syrphinae visit in order to preserve them in the green areas around farmland. However, there is a lack of clarity about the preferred flowers of Syrphinae and the plant species on which they depend [16].

We have investigated the relationship between 43 weed species around farmland and the frequency of flower visits from Syrphinae. Consequently, we demonstrated that flowers frequently visited by Syrphinae are yellow $(\mathrm{p}=0.046)$, flat $(p=0.0049)$, and have a simple shape $(p=0.0092)$ (Saruta, and Inagaki unpublished). Therefore, flat and simple 
shapes are more important than flower color for the Syrphinae (Saruta, and Inagaki unpublished).

The annual blue-eyed grass (Sisyrinchium rosulatum) is a typical flower with a flat and simple shape. However, we did not observe any visiting Syrphinae in any population of S. rosulatum during our field studies in 2017 and 2018 (Nakatani and Inagaki unpublished, Saruta, and Inagaki unpublished). Therefore, there is a possibility that the Syrphinae avoid S. rosulatum. The mechanism enabling Syrphinae to avoid S. rosulatum is thought to be related to the ultraviolet rays and flower fragrance. We confirmed there was no difference in the quantity of ultraviolet rays between $S$. rosulatum (avoided by Syrphinae) and Oxalis corniculata (preferred by Syrphinae) (Nakatani and Inagaki unpublished). Hence, it is speculated that the quantity of ultraviolet rays is not the cause of the Syrphinae's aversion to S. rosulatum.

In this study, therefore, we hypothesized that the Syrphinae avoid S. rosulatum due to the flower scent, which acts as a flower filter, and we found that Syrphinae did not visit $S$. rosulatum flowers even under restricted, closed conditions, and demonstrated the Syrphinae's aversion to the flower scent of $S$. rosulatum using a T-shaped tube.

\section{Materials and Methods}

\subsection{Plant material and tested Syrphinae}

Sisyrinchium rosulatum, Oxalis corniculata (Oxalis), and tested Syrphinae were collected from the field of Shizuoka University (Kariyado, Fujieda, Japan).

\subsection{Observations on the visiting of Syrphinae to $S$. rosulatum flowers in a closed environment}

Three white flowers and three purple flowers of $S$. rosulatum, and three flowers of Oxalis, which were selected by the Syrphinae (as a positive control), were placed randomly in a plastic box $(40 \mathrm{~cm} \times 25 \mathrm{~cm} \times 28 \mathrm{~cm}$ ). One Syrphinae was released in a plastic box and observed and counted for visiting and pollinating S. rosulatum and Oxalis for 20 minutes. Consequently, we removed only Oxalis, and released another Syrphinae in a plastic case with three white flowers and three purple flowers of $S$. rosulatum. One test was repeated six times, and the position of the flowers was rearranged for each test.

\subsection{Preference tests using a T-shaped pipe}

A plastic bag with crushed flowers (S. rosulatum, Oxalis) was connected to both ends of the T-shaped tube (diameter $1 \mathrm{~cm}$ ) so that the flower's scent was transmitted to a T-shaped tube. One Syrphinae was placed at the T-shaped tube entrance to observe whether it moved to the left or right. Three experiments were carried out: 1) S. rosulatum-empty; 2) Oxalis-empty; and 3) S. rosulatum-Oxalis. The samples were randomly switched on to the left or right for each test. Each examination was repeated 35-40 times.

\subsection{Statistical Analysis}

All statistical analyses were performed using the BellCurve for Excel 5.0 (Social Survey Research Information Co., Ltd.) software.

\section{Results and Discussion}

\subsection{The visit of Syrphinae to $S$. rosulatum flowers in a closed environment}

Visiting and pollination by Syrphinae were frequently observed on Oxalis flowers (Figure 1). In contrast, visiting Syrphinae was not observed on S. rosulatum flowers (Figure 1). This finding indicated that the Syrphinae preferred Oxalis flowers to S. rosulatum flowers. Secondly, when we removed the Oxalis, visiting Syrphinae was hardly observed (Figure 1). Although one Syrphinae visited S. rosulatum white flowers once, no pollination was observed. It, therefore, appears from these results that Syrphinae may not only have a low preference for $S$. rosulatum flowers but may also avoid them.

\subsection{Preference tests using a T-shaped pipe}

In $S$. rosulatum-empty examination, the frequency of selecting $S$. rosulatum was statistically lower than that of empty cells $(\mathrm{p}=0.0004)$ (Figure 2 ). In the Oxalis-empty examination, there was no significant difference between the choices $(\mathrm{p}=0.29)$. In the $S$. rosulatum-Oxalis examination, Syrphinae moved more toward Oxalis than $S$. rosulatum $(\mathrm{p}=$ 0.0081). The results from the $S$. rosulatum-empty and S. rosulatum-Oxalis examination showed that the Syrphinae tend to avoid S. rosulatum. In addition, it is suggested that Syrphinae avoid the flower by detecting the scent because, in this experiment, the Syrphinae could not visually identify the flowers. It is well known that flowers volatilize scents to attract pollinators [17]. However, some insects are preferable as pollinators, and some do not depend on a particular plant species. In comparison to bees, the Syrphinae have advantages, such as operating at low temperatures and not requiring 
much honey [18]. In contrast, the Syrphinae have some drawbacks, such as moving only short distances and making random visits without identifying the plant species. For this reason, many plants that use bees as pollinators prevent invasion by Syrphinae by complicating their flower structure. It is suggested that the Syrphinae might be an unfavorable pollinator for S. rosulatum. However, the flowers of $S$. rosulatum are not complicated, but rather have the flat and simple flower structure preferred by the Syrphinae. It has been suggested that flowers emit specific chemicals to attract particular pollinators and repel other, less useful, insects [19]. Studies on floral scents and their repellent actions have been conducted mostly in flowers such as sexually deceptive orchids and corpse flowers [19]. Recently, it has been reported that some common trees also have floral filters [19].

Our results indicate the possibility that $S$. rosulatum, a common weed, repels Syrphinae with chemicals. On the other hand, it is considered that the preference of Syrphinae for Oxalis is not due to the scent of the flowers, but to the shape and color of the flowers, because there was no difference in selection between Oxalis and empty in the Oxalis-empty examination.
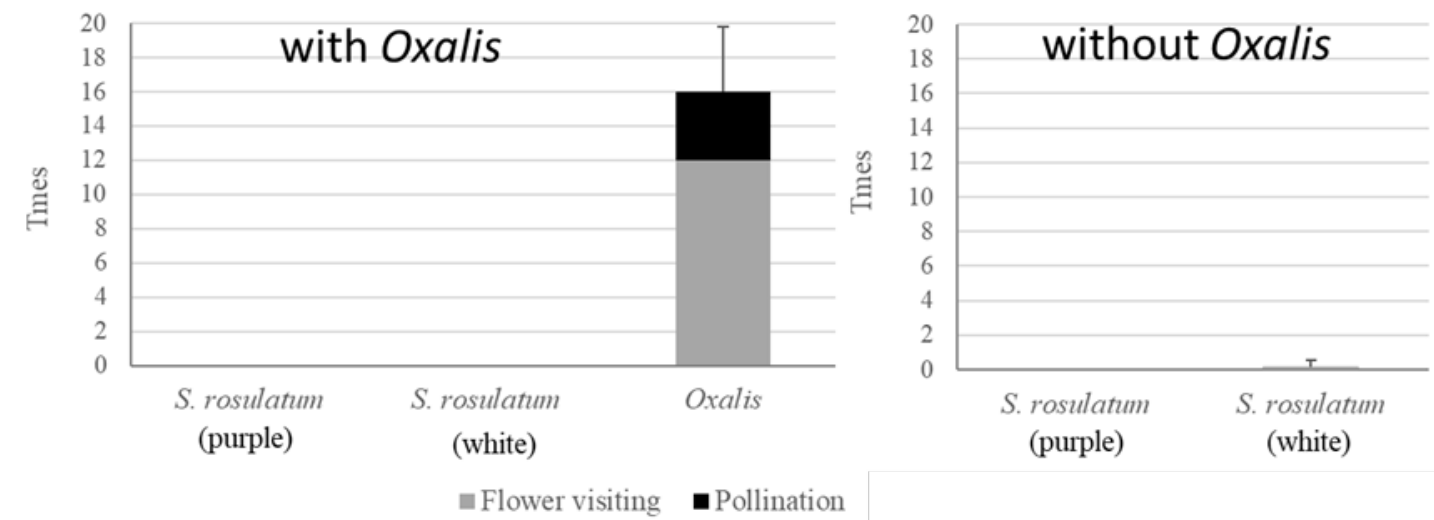

Figure 1. The preference of Syrphinae for S. rosulatum and Oxalis flowers. (Mean \pm SD)

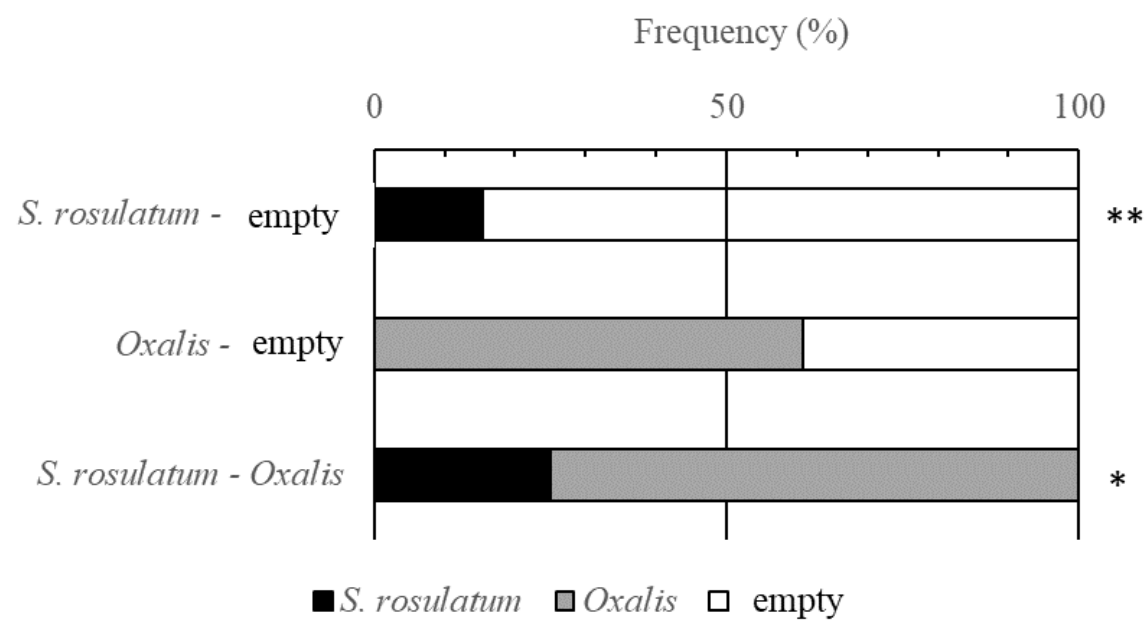

Figure 2. The preference tests Syrphinae using a T-shaped pipe $(* *, *$ indicate significantly difference at $1 \%, 5 \%$ level respectively of Chi-squared test).

\section{Conclusion}

Our study results show the possibility of a chemical floral filter in S. rosulatum to deter Syrphinae hoverflies. It is well established that the scent of plants attracts pollinators to flowers [17]. In addition, the phenomenon of flower se-lection and avoidance due to scent, as shown in our results, is essential to the understanding of interactions between flowers and pollinators. However, although it is inferred from this result that Syrphinae avoids S. rosulatum flowers due to factors other than vision, it is not sufficiently clear whether it is the scent. In this regard, further research is needed, such as the identification of the scented substances.

\section{Acknowledgements}

This work was supported by JSPS KAKENHI Grant Number J 18H02286. 


\section{References}

[1] Millennium Ecosystem Assessment. (2005). Ecosystems and Human Well-Being: Synthesis. Island Press, Washington, DC.

[2] Antoine, C. D. (2019). Functional Biodiversity and the Concept of Ecological Function. From Assessing to Conserving Biodiversity (pp. 297-316), Berlin: Springer.

[3] Tilman, D. (2001). Functional diversity. In Encyclopedia of biodiversity, 3, pp. 109-120.

[4] Naeem, S. (2002). Functional biodiversity. In H. A. Mooney \& J. G. Canadell (Eds.), Encyclopedia of global environmental change (pp. 20-36). Chichester/Rexdale: Wiley.

[5] Petchey, O. L., \& Gaston, K. J. (2006). Functional diversity: Back to basics and looking forward. Ecology Letters, 9, 741-758.

[6] AFFRC, NIAES and NIAS (Agriculture, Forestry and Fisheries Research Council, National Institute for Agro-Environmental Sciences and National Institute of Agrobiologicalciences). (2012). Indicator Animals of Functional Agrobiodiversity: A Survey and Evaluation Manual. (in Japanese). http://www.niaes.affrc.go.jp/techdoc/shihyo/ Viewed 24 Aug. 2020.

[7] Department for Environment, Food and Rural Affairs (DEFRA). (2007). An introductory guide to valuing ecosystem services. https://assets.publishing.service.gov.uk/government/uploads/system/uploads/attachment_data/file/69192/pb12852-eco-valuing071205.pdf. Viewed 24 Aug. 2020.

[8] Storkey, J. (2006). A functional group approach to the management of UK arable weeds to support biological 153 diversity. Weed Research, 46, 513-522.

[9] Kakimoto, K., Matsuhira, K., Inoue, H., Nakasima, A., Ito, Y., Abe, J., Ohta, I., Mizutani, N., \& Ohno, K. (2016). Effectiveness of conservation biological control against the cotton aphid Aphis gossypii Gloverin okra fields I. Attractiveness of beneficial hoverflies by some varieties or species of basil Ocimum basilicum L. Annual Report of Kansai Plant Protection association, 58, 41-44. (in Japanese)

[10] Tanaka, K. (2016). Functional Biodiversity Indicators and their Evaluation Methods in Japanese Farmlands. In The Challenges of Agro-Environmental Research in Monsoon Asia (pp. 159-169), Tsukuba: National Institute for Agro-Environmental Sciences (NIAES).

[11] Pontin, D. R., Wade, M. R., Kehrli, K., \& Wratten S. D. (2006). Ann. Appl. Biol. 148, 39-47.

[12] Sadeghi, H. (2008). Abundance of adult hoverflies (Diptera: Syrphidae) on different flowering plants. Caspian Journal of Environmental Science 6, 47-51.

[13] Graham, E. R., \& Gilbert, F. (2011). The natural history of hoverfries. Devon: Forest Text, UK.

[14] Hogg, B. N., Bugg, R. L., \& Daane, K. M. (2011). Attractiveness of common insectary and harvestable floral resources to beneficial insects. Biol. Control, 56, 76-84.

[15] Laubertie, E. A., Wratten S. D., \& Hemptinne J. L. (2012). The contribution of potential beneficial insectary plant species to adult hoverfly (Diptera: Syrphidae) fitness. Biol. Control, 61, 1-6.

[16] Ohno, K., Takenoyama, K, \& Kitayama, Y. (2012). Development and evaluation of Insector plant. Annual report of the association for plant protection of Kyushu, 59, 123-124. (in Japanese)

[17] Tanaka, H. (2000). Color and odor of Japanese wild flowers in relation to pollinators. Honeybee science, 21, 107-113.

[18] Marriott, C. G., \& Holloway, G. J. (1998). Colour Pattern Plasticity in the Hoverfly, Episyrphus balteatus: The Critical Immature Stage and Reaction Norm on Developmental Temperature. Journal of insect physiology, 44, 113-119.

[19] Omura, H., Honda, K., \& Hayashi, N. (2000). Floral Scent of Osmanthus fragrans Discourages Foraging Behavior of Cabbage Butterfly, Journal of Chemical Ecology, 26, 655-666. 